less than 900 million years after the Big Bang.

Astrophys. J. 779, 24 (2013)

\section{BIOTECHNOLOGY}

\section{CRISPR corrects genetic disease}

A system for editing genes has now been used to repair disease-related mutations in mice and human stem cells, highlighting the technology's therapeutic potential.

The recently developed CRISPR system uses an RNA strand matching a target gene to guide a bacterial enzyme, Cas9, to excise the gene. Jinsong Li and his colleagues at the Shanghai Institutes for Biological Sciences in China used the technique in fertilized mouse eggs to correct the mutated Crygc gene, which causes cataracts. The mice grew into healthy adults that bore normal offspring.

In a separate paper, Hans Clevers at the Hubrecht Institute in Utrecht, the Netherlands, and his team repaired the cystic fibrosis gene, CFTR, in cultured intestinal stem cells obtained from patients with the disease. Cell Stem Cell 13,653-658; 659-662 (2013)

\section{METEOROLOGY}

\section{Satellite improves storm forecasts}

Data from a US Earthobserving satellite could help improve the accuracy of predictions of hurricane track and strength.

When generating hurricane forecasts, the US National Weather Service does not use real-time information from weather satellites. But Xiaolei Zou at Florida State University in Tallahassee and her colleagues looked at the effect of including data from the
Suomi NPP satellite, launched in 2011, on hurricane forecasts.

The satellite's microwave instrument measures air temperature and humidity.

Incorporating Suomi data into the government's hurricane model for four 2012 storms, including Sandy (pictured), made for more accurate forecasts of track and intensity. The work suggests a way to improve the notoriously difficult predictions of storm strength. J. Geophys. Res. Atm. 118, 11558-11576 (2013)

\section{NEUROSCIENCE}

\section{Primate brain} makes oestrogen

Ovaries are the main producers of oestrogen but when they give out, the brain in monkeys can take over in making the hormone.

Ei Terasawa and her colleagues at the University of Wisconsin in Madison removed the ovaries of female rhesus monkeys (Macaca mulatta) and briefly stimulated the animals' brains with oestrogen or an electrical current. The brain's hypothalamus region began producing its own oestrogen, along with other hormones involved in reproduction.

If human brains have the same capability, targeting this oestrogen source could be a way to treat diseases such as depression that may be linked to oestrogen imbalances, the authors say.

J. Neurosci. 33, 19051-19059 (2013)

\section{ECOLOGY \\ Why rabies hangs on after bat culls}

Culling vampire bats in South America to combat the spread of rabies could be having the opposite effect, according to a modelling study.

Vampire bats (Desmodus rotundus) transmit the rabies virus by biting humans and livestock.

COMMUNITY CHOICE

The most viewed papers in science

ENVIRONMENTAL SCIENCE

\title{
Gas production contaminates water
}

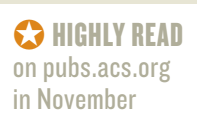

Waste water from oil and gas production is contaminating surface waters and sediments in western Pennsylvania - even after it has been treated.

In the United States, such waste is sometimes sent to treatment facilities and then discharged into streams and rivers. Nathaniel Warner, Avner Vengosh and their colleagues at Duke University in Durham, North Carolina, analysed the effluent in 2010-12 at a facility that treated water from gas wells in the Marcellus Shale. They looked at samples taken upstream and downstream of the facility, and found increased contaminants such as chloride and bromide downstream.

Although treatment lowered the levels of barium and radium in the waste water, radioactivity levels from radium in river sediments near the facility were 200 times greater than background levels, and were above regulatory limits.

The authors say that the elevated radium levels suggest a risk of radioactivity accumulating in wastewater disposal areas, and that better treatment technologies are needed to reduce contamination.

Environ. Sci. Technol. 47, 11849-11857 (2013)

Julie Blackwood at Williams

College in Williamstown,

Massachusetts, and her colleagues analysed field data on individual bats collected from 17 colonies in Peru between 2007 and 2010. They found that the rabies virus probably does not persist in a single bat colony, but instead is spread between colonies by wandering bats. Most infections do not kill bats but confer temporary immunity, which also maintains the levels of virus.

Bat culls, the researchers note, may increase movement of bats and thus promote the spread of the disease.

Proc. Natl Acad. Sci. USA http://doi.org/qb9 (2013)

\section{PALAEONTOLOGY}

\section{Ancient reptiles stuck to the air}

Flying reptiles that went extinct around 65 million years ago probably did not spend much time on water even though fossils of the creatures with fish in their stomachs have been found in ancient oceans and lakes.

David Hone, at Queen Mary University in London, and Donald Henderson at the Royal Tyrrell Museum of Palaeontology in Drumheller, Alberta, tested the floatingpterosaur hypothesis by creating computer models of what four pterosaurs might have looked like afloat. They took account of the reptiles' bone density, skeleton shape and other factors. The models suggest that, under most conditions, pterosaurs would have oriented their heads horizontally to the water, leaving the bottom onequarter to one-third of their heads submerged.

Pterosaurs would have risked drowning if they spent too much time on the water, the researchers say.

Palaeogeogr. Palaeoclimatol. Palaeoecol. http://doi.org/qcf (2013)

\section{NATURE.COM}

For the latest research published by Naturevisit:

www.nature.com/latestresearch 